\section{artelogie}

\section{Artelogie}

Recherche sur les arts, le patrimoine et la littérature de l'Amérique latine

10 | 2017

Après le paysage : l'art, l'inscription et la représentation de la nature en Amérique latine aujourd'hui

\title{
Est-ce qu'il y a un monde pour vivre? Essai sur les peurs et les fins, de Débora Danowski e Eduardo Viveiros De Castro
}

\section{Fábio Zuker}

\section{(2) OpenEdition \\ Journals}

Édition électronique

URL : http://journals.openedition.org/artelogie/939

DOI : 10.4000/artelogie.939

ISSN : 2115-6395

Éditeur

Association ESCAL

Référence électronique

Fábio Zuker, «Est-ce qu'il y a un monde pour vivre? Essai sur les peurs et les fins, de Débora Danowski e Eduardo Viveiros De Castro », Artelogie [En ligne], 10 | 2017, mis en ligne le 05 avril 2017, consulté le 23 septembre 2020. URL : http://journals.openedition.org/artelogie/939 ; DOI : https://doi.org/ 10.4000/artelogie.939

Ce document a été généré automatiquement le 23 septembre 2020

Association ESCAL 


\section{Est-ce qu'il y a un monde pour vivre? Essai sur les peurs et les fins, de Débora Danowski e Eduardo Viveiros De Castro}

Fábio Zuker

\section{RÉFÉRENCE}

Débora DANOWSKI e Eduardo VIVEIROS DE CASTRO, Há mundo por vir? Ensaio sobre os medos e os fins, Florianópolis, Desterro, Cultura e Barbárie e Instituto Socioambiental, 2014, 176p.

1 La tentative de produire une " pensée et une mythologie conformes à notre époque » une réflexion cosmopolitique dialoguant avec la pensée amérindienne - est au fondement de l'essai écrit par Débora Danowski et Eduardo Viveiros de Castro. Navigant avec une rare aisance entre les thématiques propres aux champs de l'ethnologie, de la philosophie politique et de la philosophie de l'histoire, l'ouvrage confère une place centrale à la peur de la fin du monde. Cette dernière remplace alors, dans l'imaginaire moderne, le rôle joué, auparavant, par le messianisme.

Qualifié par les auteurs d'"anthropocentrique", le cosmopolitisme moderne concevrait l'être humain comme le stade ultime d'une évolution tout au long de l'histoire. La prétention de dominer la nature par les sciences, marquée par l'histoire du progrès, a eu pour résultat l'effet inverse : la nature répond de manière violente par un imminent cataclysme climatique et une humanité réduite à une couche géologique, l'anthropocène.

Pour ne jamais avoir eu de nature et pour n'avoir pas eu à s'en libérer, ce qui équivaut à ne jamais avoir été moderne, les Amérindiens, entre autres peuples non-modernes, peuvent nous enseigner comment vivre après la fin du monde - un monde disparu il y a cinq siècles avec l'arrivée des Européens. Danowski et Viveiros de Castro considèrent la 
pensée cosmopolitique amérindienne comme marquée par l'anthropocentrisme, où le monde et la vie possèdent des liens inextricables; il est alors impossible de concevoir le monde sans humain. Selon les dires alarmants du chaman yanomami Davi Kopenawa, les blancs n'y croient pas, mais lorsque le ciel tombera, il tombera sur chacun d'entre nous.

4 Considérant la critique du capitalisme comme insuffisante pour rendre compte de la crise planétaire, il s'avère impératif d'abandonner le mythe du progrès moderne. Maintenant que la fin du monde est devenue une réalité, les expériences menées contre l'État et l'économie de marché, à l'image du mouvement politique maya - même après sa propre fin du monde -, sont évoquées par les auteurs comme autant d'alternatives imaginaires pour la politique.

\section{AUTEURS}

\section{FÁBIO ZUKER}

Master en sciences sociales, EHESS-Paris

fabiozuker[at]gmail.com 